\title{
Effects of planting distance and depth on PTO load spectrum of a small riding-type transplanter
}

\author{
Wan-Soo Kim ${ }^{1,2}$, Yeon-Soo Kim ${ }^{1,3}$, Taek-Jin Kim ${ }^{1,2}$, Kyu-Chul Nam ${ }^{4}$, Tae-Bum Kim ${ }^{5}$, \\ Tae-Ho Han ${ }^{6}$, Ryu-Gap $\mathrm{Im}^{6}$, Yong-Hyeon Kim ${ }^{7}$, Yong-Joo Kim ${ }^{1,2 *}$ \\ (1. Department of Biosystems Machinery Engineering, Chungnam National University, Daejeon 34134, Republic of Korea; \\ 2. Department of Smart Agriculture Systems, Chungnam National University, Daejeon 34134, Republic of Korea; \\ 3. Convergence Agricultural Machinery Group, Korea Institute of Industrial Technology, Gimje 54325, Republic of Korea; \\ 4. Certification, Warranty, Inspection and Standardization Team, Korea Agricultural Machinery Industry Cooperative, \\ Cheonan 31041, Republic of Korea; 5. Diesel Service Korea Co. Ltd., Daejeon 34357, Republic of Korea; \\ 6. Agricultural Machinery Certification Team, Foundation of Agricultural Technology Commercialization and Transfer, \\ Iksan 54667, Republic of Korea; \\ 7. Gint Co. Ltd., Suwon 16225, Republic of Korea)
}

\begin{abstract}
The aim of this study was to analyze the effects of the planting distance and depth on the power take-off (PTO) load spectrum of a small riding-type transplanter for the optimal design of the transplanter. To measure load data during actual planting operation, a load measurement system was developed using a torque sensor, a data acquisition system, and an inverter. Field experiments were conducted at four planting distances $(26 \mathrm{~cm}, 35 \mathrm{~cm}, 43 \mathrm{~cm}$, and $80 \mathrm{~cm})$ and three planting depths $(85 \mathrm{~mm}, 105 \mathrm{~mm}$, and $136 \mathrm{~mm})$ in a field with similar soil conditions. The measured load data were inverted into a load spectrum using rain-flow counting and Smith-Watson-Topper (SWT) methods. The safety factor of a transplanter according to the planting conditions was analyzed using the converted load spectrum and commercial software. The load spectrum for all planting conditions showed torque ratios similar within a high cycle region of $10^{8}$ to $10^{9}$. The torque ratio increased when the planting depth increased and planting distance decreased in the low cycle region under less than $10^{8}$ cycles. The safety factors of the PTO driving gear and the driven gear increased as the planting distance increased at all planting depths. When the planting depth decreased at the same planting distance, the safety factor of the PTO gears increased. The results of this study might provide useful information for a transplanter PTO design considering the working load according to the various planting conditions.
\end{abstract}

Keywords: transplanter, planting distance, planting depth, power take-off, load spectrum, safety factor DOI: $10.25165 /$ j.ijabe.20201302.4187

Citation: Kim W-S, Kim Y-S, Kim T-J, Nam K-C, Kim T-B, Han T-H, et al. Effects of planting distance and depth on PTO load spectrum of a small riding-type transplanter. Int J Agric \& Biol Eng, 2020; 13(2): 57-63.

\section{Introduction}

The working time required for the transplanting of seedlings is $18.4 \mathrm{~h}$ per 10 acres based on manpower in Korea, accounting for $18.7 \%$ of the working time of farmers ${ }^{[1]}$. A transplanter was

\section{Received date: 2018-02-22 Accepted date: 2019-12-10}

Biographies: Wan-Soo Kim, PhD candidate, research interests: agricultural tractor and power transmission system, Email: wskim0726@gmail.com; Yeon-Soo Kim, PhD candidate, research interests: load measurement and analysis based on terramechanics, Email: kimtech612@gmail.com; Taek-Jin Kim, PhD candidate, research interests: design of power transmission system, Email: taekjin79@nate.com; Kyu-Chul Nam, Deputy General Manager, research interests: standardization of agricultural tractor, Email: kc@kamico.or.kr; Tae-Bum Kim, Engineering Manager, research interests: diesel engine for agriculture, Email: dieselservice@nate.com; Tae-Ho Han, Senior Researcher, research interests: performance evaluation of agricultural machinery, Email: hth1211@efact.or.kr; Ryu-Gap Im, Senior Researcher, research interests: performance evaluation of agricultural machinery, Email: limso@efact.or.kr; Yong-Hyeon Kim, CEO, research interests: intelligent system for agriculture, Email: yonghyeon.kim@gintlab.com.

Corresponding author: Yong-Joo Kim, PhD, Associate Professor, research interests: agricultural tractor and power transmission system, Dept. of Biosystems Machinery Engineering, Chungnam National University, Daejeon, Republic of Korea. Tel: +82-42-821-6716, Email: babina@cnu.ac.kr. developed to reduce the time and labor required for the transplanting of seedlings, and is widely used to improve the convenience of transplanting ${ }^{[2]}$. The global transplanter market is estimated to grow at a CAGR of $9.4 \%$ by $2022^{[3]}$. As the transplanter market increases, it is necessary to secure product competitiveness of the transplanter, such as a low price and high quality. A vegetable transplanter is mainly used in an upland field, the environmental conditions of which are harsh including hard soil, gravel, and stone. A transplanter has various working conditions in terms of the planting depth and planting distance, and different combinations of the planting depth and planting distance are used to provide suitable planting conditions depending on the crop type and field conditions ${ }^{[4-6]}$. Because the planting distance and planting depth determine the rotational cycle of the transplanter power take off (PTO) and depth of the penetration of the transplanter hopper, respectively, the planting distance and planting depth affect the fatigue life and durability of the transplanter ${ }^{[4]}$. Because a transplanting operation is carried out by transmitting power from the engine to the transplanting part through the PTO, most of the load of the transplanter occurs at the $\mathrm{PTO}^{[7]}$. Thus, it is necessary to measure and analyze the PTO load of the transplanter based on the planting conditions through a field operation for the optimal design of the transplanter considering the 
field working load.

Studies on the applications of field load data such as the load spectrum, load severity, and safety have been widely conducted in the field of agricultural machinery ${ }^{[8]}$. In particular, most studies that measure and analyze field data have mostly focused on tractors in the area of agricultural machinery ${ }^{[9-11]}$. Kim et al. ${ }^{[12]}$ measured the load of the transmission and driving axle according to the gear selection and field site during plowing operations, and analyzed the load spectrum. The results of the spectrum analysis revealed that the effect of the plowing speed on the load spectrum was more significant at the input shaft of the transmission than at the final drive shaft. Jang et al. ${ }^{[13]}$ analyzed the safety factor of the PTO gear face width for an agricultural tractor using simulation software based on the ISO standard. Lee et al. ${ }^{[14]}$ measured and analyzed the torque load acting on the PTO shaft of a $75 \mathrm{~kW}$ agricultural tractor according to the gear selection during a rotary tillage and baler operation in Korean upland fields. Most studies on a transplanter have focused on the development of a planting device such as a hopper ${ }^{[15-17]}$, control of the transplanting part ${ }^{[18]}$, and a load data analysis according to the operating conditions of the transplanter ${ }^{[4,5]}$. Lim et al. ${ }^{[5]}$ developed an electric transplanter by replacing its engine-driven system with an electric motor-driven system, and measured the current according to the planting distance to provide useful information for the optimal design of an electric drive system. As a result, the total power required of the transplanter at a planting distance of $26 \mathrm{~cm}$ was 1.57 - and 2.2-times higher than at a planting distance of $42 \mathrm{~cm}$ and $63 \mathrm{~cm}$, respectively. Because the transplanter conducts a transplanting of the seedlings based on the PTO power, the PTO is the most important among the various components of a transplanter. Kim et al. ${ }^{[4]}$ measured and statistically analyzed the PTO torque according to the planting conditions for a planting depth of two levels and a planting distance of four levels. As a result, the PTO torque at low- and middle-level planting depths at a planting distance of $26 \mathrm{~cm}$ was 2.95- and 2.82-times higher than at a planting distance of $80 \mathrm{~cm}$, respectively. These previous studies show that the working conditions have a significant effect on the transplanter. However, because the PTO load has a variable pattern, the load data must be analyzed in consideration of the mean and amplitude in order to be applied to the optimal design of the transplanter. Therefore, it is necessary to analyze PTO load spectrum according to the planting distance and depth during transplanting period and to suggest the optimal design guideline considering the magnitude and amplitude of load data.

The aim of this study was to suggest guidelines for the optimal design of the PTO by analyzing the PTO load spectrum and the safety factor using the actual field load data of the transplanter according to the planting distance and planting depth. The specific objectives were (1) to measure the loads acting on the PTO of the transplanter according to the planting distance and depth during actual planting operation, (2) to analyze the measured load data and convert measured load data to load spectrum, and (3) to analyze the safety factor of PTO gear according to the planting conditions using simulation software.

\section{Materials and methods}

\subsection{Power transmission system of transplanter}

The two-row riding-type vegetable transplanter (PF2R, Yanmar, Japan) was used in this study. The weight and dimensions of the transplanter are $615 \mathrm{~kg}$ and $3160 \mathrm{~mm} \times 1725 \mathrm{~mm} \times 1925 \mathrm{~mm}$ (length $\times$ width $\times$ height), respectively. The rated power of the transplanter is $7.1 \mathrm{~kW}$ at a rated engine rotational speed of $3600 \mathrm{r} / \mathrm{min}$. The rated torque of the transplanter was calculated as $18.8 \mathrm{~N} \cdot \mathrm{m}$ using the rotational speed and rated power. The transplanter adopted a hydraulic mechanical transmission (HMT), one of the continuously variable transmissions, and the gear stage consists of two forward gears and one reverse gear. The planting distances of the transplanter have a total of ten gear stages from 26 to $80 \mathrm{~cm}$, and the planting depths have a total of ten gear stages from 85 to $136 \mathrm{~mm}$. The planting distance is the length between the transplanted seedlings, and the planting depth is the length between the depth of the planted seedlings and the soil surface $^{[4,5,7,15]}$. The power of the transplanter is divided into the driving shaft and PTO through a belt pulley, as shown in Figure 1. The power input through the PTO is transferred to the lateral transfer shaft for seedbed interval control and to the transplanting part for field operations. The input torque of the transmission and PTO shaft based on the belt pulley ratio is 1.21 times the engine torque.

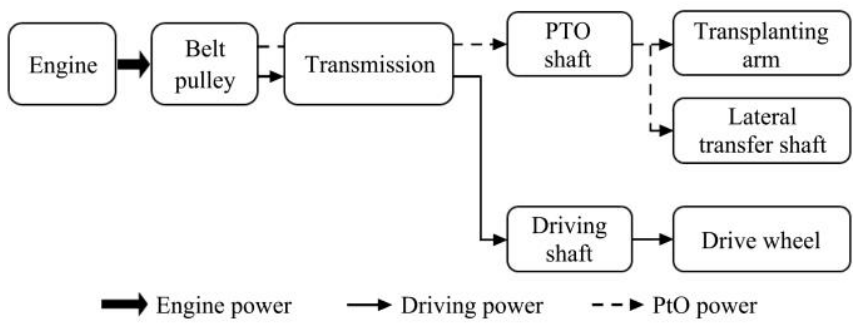

Figure 1 Schematic diagram of the power flow for the transplanter

\subsection{PTO load measurement system}

To measure PTO load data, load measurement system was developed using a torque sensor (TRS 605, FUTEK Co., USA), a data acquisition system (NI USB-6212, National Instrument, USA) to acquire PTO signals, and an inverter (DP-412, DARDA, Korea) to provide power for a laptop computer and PTO sensor, as shown in Figure 2. The PTO torque sensor of the transplanter was installed between the output of the belt pulley and the input of the transplanting part. The PTO torque sensor was selected by considering the torque that can occur on the PTO shaft by the engine torque, and the belt pulley ratio and operation temperature range of the transplanter. Torque sensors used in this study can measure torque up to $100 \mathrm{~N} \cdot \mathrm{m}$ and rotational speed up to $7000 \mathrm{r} / \mathrm{min}$. To collect and monitor the load data, the measurement program was developed based on LabVIEW (Version 2017, National Instrument, USA).

\subsection{Experiment method}

The field experiment was conducted on upland fields with similar sizes $\left(2000 \mathrm{~m}^{2}\right.$, i.e., $\left.100 \mathrm{~m} \times 20 \mathrm{~m}\right)$ in Korea (latitude 36.296064, longitude 127.561509) in July, 2016 for a 1-month period. To improve the reliability of data, the field operation was conducted by an experienced operator and was repeated five times for each planting distance and depth, as shown in Figure 3a. The load acting on the transplanter PTO depends on numerous factors, such as the crop types, planting distances, planting depths, and ground speeds. Because it is difficult to consider all factors in this study, planting distance and planting depth were selected as variables of the most important conditions. The planting distance, planting depth, and ground speed were selected through a survey of farmers. The planting conditions were selected as planting distances of $26 \mathrm{~cm}, 35 \mathrm{~cm}, 43 \mathrm{~cm}$, and $80 \mathrm{~cm}$ and planting depths of $85 \mathrm{~mm}, 105 \mathrm{~mm}$, and $136 \mathrm{~mm}$. The forward gear stage of the transplanter was set $2^{\text {nd }}(0.9 \mathrm{~m} / \mathrm{s})$. Because transplanter perform 
the task of penetrate the transplant hopper into the soil, the physical condition of the soil is one of the factors affecting the workload. Thus, the physical environment of the soil as a reference of the measured transplanter PTO load was obtained as shown in Figure $3 b^{[19]}$. The soil moisture and electric conductivity were measured using a soil sensor (WT100B, RF sensor, Seoul, Korea). The

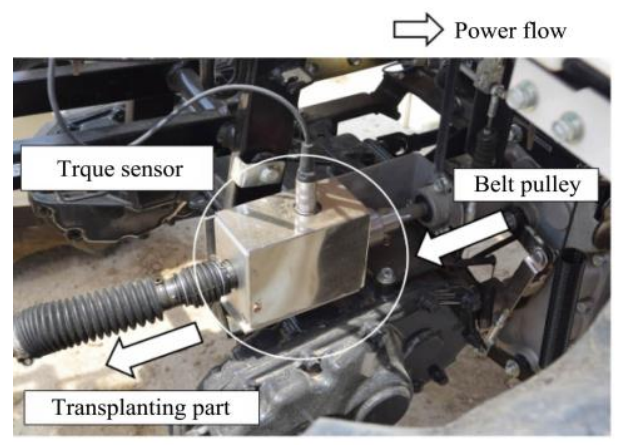

a. Torque sensor installed on PTO shear stress was measured using torque wrench (CDB25Nx10D, TOHNICHI, USA) and cone index was measured using a soil penetrometer (Dik-5530, Daiki, Saitama, Japan). The averaged cone penetration index of $0-25 \mathrm{~cm}$ was $2256 \mathrm{kPa}$. The moisture content, electric conductivity, and shear stress were $32.2 \%$, $2.25 \mathrm{dS} / \mathrm{m}$, and $22.3 \mathrm{~N} \cdot \mathrm{m}$, respectively, as shown in Table 1 .

Figure 2 PTO load measurement system

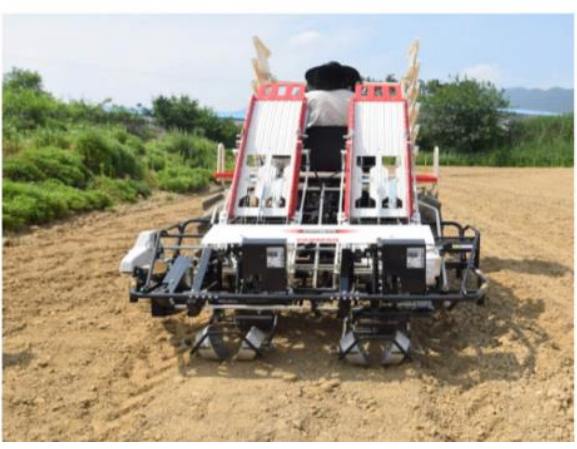

a. Field experiment

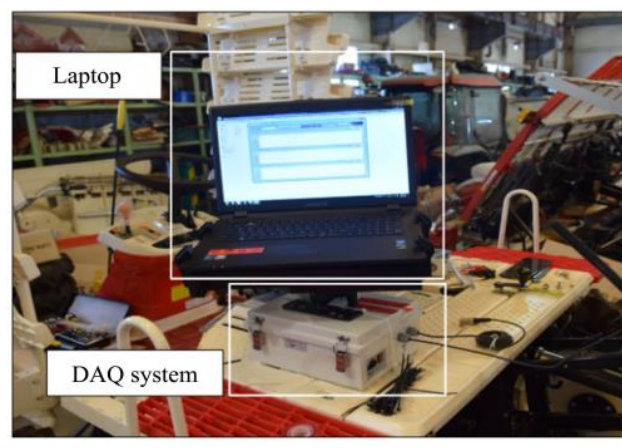

b. Laptop and data acquisition system

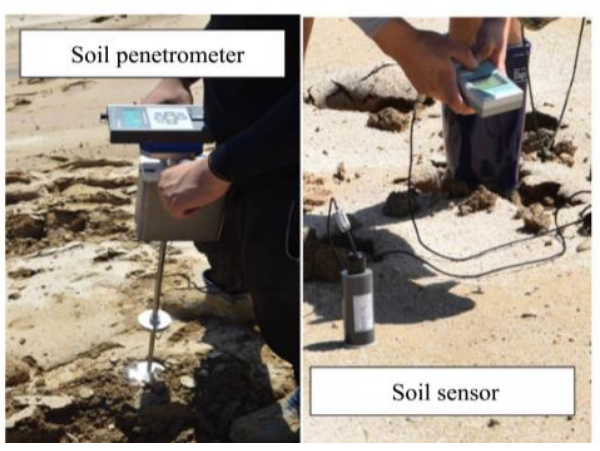

b. Soil measurement device

Figure 3 Field experiment and soil physical properties measurement of the soil

Table 1 Obtained physical properties from soil analysis

\begin{tabular}{|c|c|c|c|c|c|c|c|c|}
\hline \multirow{2}{*}{ Moisture content $/ \%$} & \multirow{2}{*}{$\begin{array}{l}\text { Electric conductivity } \\
\qquad / \mathrm{dS} \cdot \mathrm{m}^{-1}\end{array}$} & \multirow{2}{*}{$\begin{array}{c}\text { Shear stress } \\
\text { /N.m }\end{array}$} & \multicolumn{6}{|c|}{ Cone penetration index $/ \mathrm{kPa}$} \\
\hline & & & $0 \mathrm{~cm}$ & $5 \mathrm{~cm}$ & $10 \mathrm{~cm}$ & $15 \mathrm{~cm}$ & $20 \mathrm{~cm}$ & $25 \mathrm{~cm}$ \\
\hline 32.2 & 2.25 & 22.3 & 487 & 970 & 1511 & 2308 & 4318 & 3944 \\
\hline
\end{tabular}

\subsection{Load spectrum}

The methods used to analyze the transplanter PTO load differ according to their purpose. Most studies have applied a simple statistical analysis, such as the average, maximum, minimum, and standard deviation, to indicate the field load ${ }^{[4,20,21]}$. However, a simple statistical analysis is not suitable for this study, because the variation pattern of the PTO load must be considered in order to provide the guideline for the optimum design of the transplanter. In this study, to consider of the fluctuating loads, the load spectrum was created by applying rain-flow counting and Smith-Watson-Topper (SWT) models, and was expanded for the entire life of the transplanter, as shown in Figure 4. In addition, previous studies performed statistical analysis on the entire cycle, including both planting and preparation period ${ }^{[4]}$. In this case, the overall load is relatively low because of the preparation period in which no load occurs. However, the fatigue life of the transplanter is affected by the load occurring in the planting period. Therefore, in this study, the analysis was performed using only loads generated in the planting period.

The measured torque data were converted from the time domain into the frequency domain using the rain-flow counting and SWT methods because the torque was irregular. The rain-flow counting method is commonly recognized as a good cyclic

counting approach for determining the irregular $\operatorname{load}^{[22]}$. It decomposes a variable amplitude load history into simple events equivalent to individual cycles of a constant load amplitude ${ }^{[23]}$. To calculate the spectrum magnitude and remove the effects of the mean torque, the SWT method was applied using the following Equation (1):

$$
T_{e}=\sqrt{\left(t_{a}+t_{m}\right) t_{a}}
$$

where, $T_{e}$ is the equivalent torque, $\mathrm{Nm} ; t_{a}$ is the torque amplitude, $\mathrm{Nm}$; and $t_{m}$ is the mean torque, $\mathrm{Nm}$.

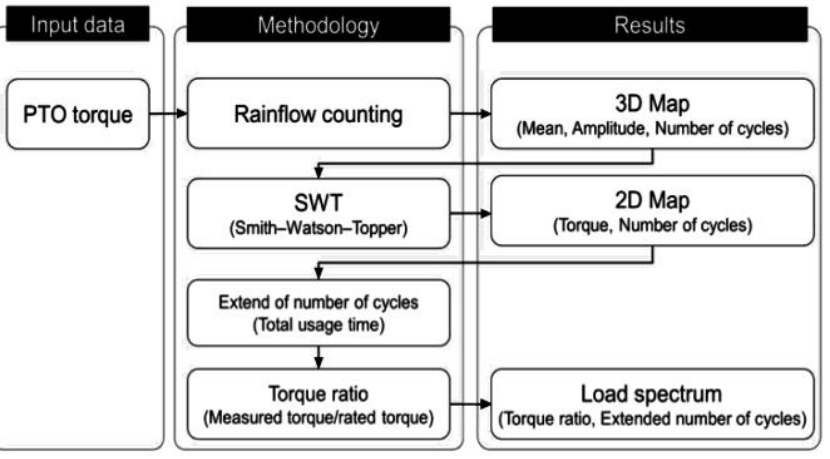

Figure 4 Procedure for converting load spectrum based on measured PTO torque 
Because the recorded time of the measured torque data was relatively short at 25 to $30 \mathrm{~s}$, the number of cycles of field operations used for analyzing the load spectrum of the transplanter according to the planting conditions was extended to the total usage time ${ }^{[14]}$. The total number of cycles of the load was calculated using Equation (2), and the entire life and annual usage time of the transplanter in Korea were 10 years and 25.5 h, respectively ${ }^{[24]}$.

$$
N_{T}=3600 N L h
$$

where, $N_{T}$ is the total number of cycles of the load; $N$ is the number of calculated cycles of the measured torque (cycles/s); $L$ is the entire life of the used transplanter, yr; and $h$ is the annual usage time of the transplanter, h/yr.

\subsection{Safety factor analysis}

The PTO gear of the transplanter should be designed to ensure the load according to the various planting conditions. An excessive safety factor increases the size and weight of the PTO gear, which increases the cost. Therefore, the proper safety factor of the transplanter should be calculated according to the planting conditions. In general, a safety factor of larger than 1 is required depending on the material properties, operation type, and load magnitude ${ }^{[10]}$. A safety factor of less than 1 can be dangerous because it could result in gear damage or a reduced service life. In this study, because the torque of the PTO shaft was measured, the torque was converted into stress, as shown in Equation (3) ${ }^{[25]}$. The diameter of the PTO shaft in this study was $14 \mathrm{~mm}$. The converted stress was used as the input condition of the PTO driving gear to calculate its safety factor. The material of the PTO gear used in this study is SCM420H. The bending and contact stresses of the PTO gear were generated at the tooth root and tooth flank as the gear was driven. The limit stresses for the tooth root and tooth flank of the PTO were 430 and $1500 \mathrm{~N} / \mathrm{mm}^{2}$. The safety factor for the bending stress at the tooth root of the PTO gear was calculated using Equation (4) ${ }^{[26]}$. The safety factor for the contact stress at the tooth flank of the PTO gear was calculated using Equation $(5)^{[26]}$. The safety factor was calculated by dividing the limit stress by the generated stress. The limit stress of the gear is a fixed value depending on the material used in the gear. Thus, the increase in load causes a decrease in the safety factor. Because these loads occur differently according to the various planting conditions, the safety factor of the PTO gear according to the planting distance and planting depth was simulated. To simulate the safety factor for the PTO gears according to the planting conditions, KISSsoft software developed by Swiss L. Kissling \& Co. AG, was used. KISSsoft is used for the modeling and analysis of mechanical elements such as gears, shafts, bearings, and gearboxes in most machinery fields using gears ${ }^{[27]}$.

$$
S=\frac{16 T}{\pi d^{3}}
$$

where, $S$ is the stress, MPa; $T$ is the equivalent torque, $\mathrm{Nm}$; and $d$ is the diameter of the shaft, $\mathrm{mm}$.

$$
\begin{gathered}
S_{F}=\sigma_{F G} / \sigma_{F} \\
S_{H}=\sigma_{H G} / \sigma_{H}
\end{gathered}
$$

where, $S_{F}$ is the safety factor for the bending stress; $\sigma_{F G}$ is the limit bending stress, $\mathrm{N} / \mathrm{mm}^{2} ; \sigma_{F}$ is the bending stress, $\mathrm{N} / \mathrm{mm}^{2} ; S_{H}$ is the safety factor for the contact stress; $\sigma_{H G}$ is the limit contact stress, $\mathrm{N} / \mathrm{mm}^{2}$; and $\sigma_{H}$ is the contact stress, $\mathrm{N} / \mathrm{mm}^{2}$.

\section{Results and discussion}

\subsection{PTO loads according to the planting conditions}

Figure 5 shows the torque levels of maximum and averaged on the PTO according to the planting conditions for the combinations of the planting distances $(26 \mathrm{~cm}, 35 \mathrm{~cm}, 43 \mathrm{~cm}$, and $80 \mathrm{~cm})$ and planting depths $(85 \mathrm{~mm}, 105 \mathrm{~mm}$, and $136 \mathrm{~mm})$, respectively. The maximum torque on the PTO for the four different planting distances of $26 \mathrm{~cm}, 35 \mathrm{~cm}, 43 \mathrm{~cm}$, and $80 \mathrm{~cm}$ at three planting depths of $85 \mathrm{~mm}, 105 \mathrm{~mm}$, and $136 \mathrm{~mm}$ during planting period were $38.9 \mathrm{~N} \cdot \mathrm{m}, 36.3 \mathrm{~N} \cdot \mathrm{m}, 31.0 \mathrm{~N} \cdot \mathrm{m}$, and $30.9 \mathrm{~N} \cdot \mathrm{m} ; 42.7 \mathrm{~N} \cdot \mathrm{m}$, $43.2 \mathrm{~N} \cdot \mathrm{m}, 34.4 \mathrm{~N} \cdot \mathrm{m}$, and $34.5 \mathrm{~N} \cdot \mathrm{m}$; and $53.0 \mathrm{~N} \cdot \mathrm{m}, 37.0 \mathrm{~N} \cdot \mathrm{m}$, $42.1 \mathrm{~N} \cdot \mathrm{m}$, and $38.0 \mathrm{~N} \cdot \mathrm{m}$, respectively as shown in Figure 5a. The averaged torque on the PTO for the four different planting distances of $26 \mathrm{~cm}, 35 \mathrm{~cm}, 43 \mathrm{~cm}$, and $80 \mathrm{~cm}$ at three planting depths of 85,105 , and $136 \mathrm{~mm}$ during planting period were $13.1 \mathrm{~N} \cdot \mathrm{m}, 13.1 \mathrm{~N} \cdot \mathrm{m}, 12.6 \mathrm{~N} \cdot \mathrm{m}$, and $10.9 \mathrm{~N} \cdot \mathrm{m} ; 14.4 \mathrm{~N} \cdot \mathrm{m}$, $13.9 \mathrm{~N} \cdot \mathrm{m}, 13.5 \mathrm{~N} \cdot \mathrm{m}$, and $12.9 \mathrm{~N} \cdot \mathrm{m}$; and $17.2 \mathrm{~N} \cdot \mathrm{m}, 15.3 \mathrm{~N} \cdot \mathrm{m}$, $15.1 \mathrm{~N} \cdot \mathrm{m}$, and $14.2 \mathrm{~N} \cdot \mathrm{m}$, respectively as shown in Figure $5 \mathrm{~b}$. The maximum PTO load of the transplanter was greater $100 \%-126 \%$, $100 \%-125 \%$, and $97 \%-139 \%$ at planting depths of $85 \mathrm{~mm}, 105 \mathrm{~mm}$, and $136 \mathrm{~mm}$ according to the planting distance, respectively. The averaged PTO load of the transplanter was greater $116 \%-120 \%$, $105 \%-112 \%$, and $106 \%-121 \%$ at planting depths of $85 \mathrm{~mm}$, $105 \mathrm{~mm}$, and $136 \mathrm{~mm}$ according to the planting distance, respectively. The average torque levels at a planting distance of $26 \mathrm{~cm}$ were greater than those at a planting distance of $80 \mathrm{~cm}$ for all planting depth levels during the field operation. For a planting depth of $136 \mathrm{~mm}$, the average torque levels were greater than those at a planting depth of $85 \mathrm{~mm}$ for all planting distance levels. The averaged PTO torque showed difference of $112 \%-121 \%$ as the planting distance adjusted from 26 to $80 \mathrm{~cm}$ at the same planting depth. The averaged PTO torque showed difference of $117 \%-130 \%$ as the planting distance adjusted from 85 to $136 \mathrm{~mm}$ at the same planting distance. Thus, the PTO torque is more affected by planting depth than by planting distance.

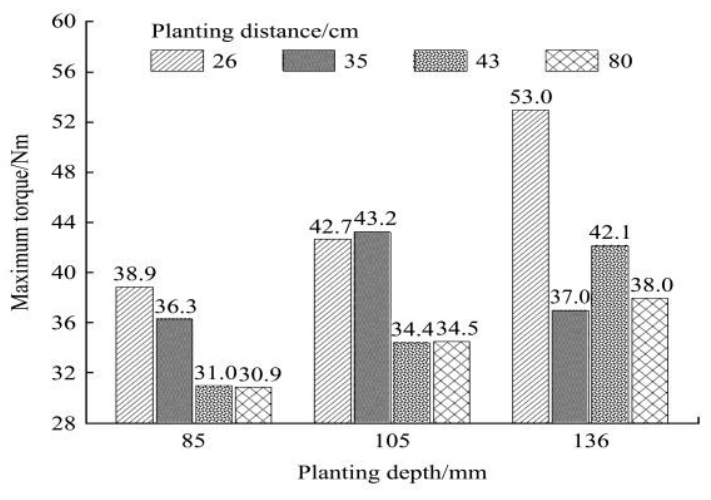

a. Maximum torque

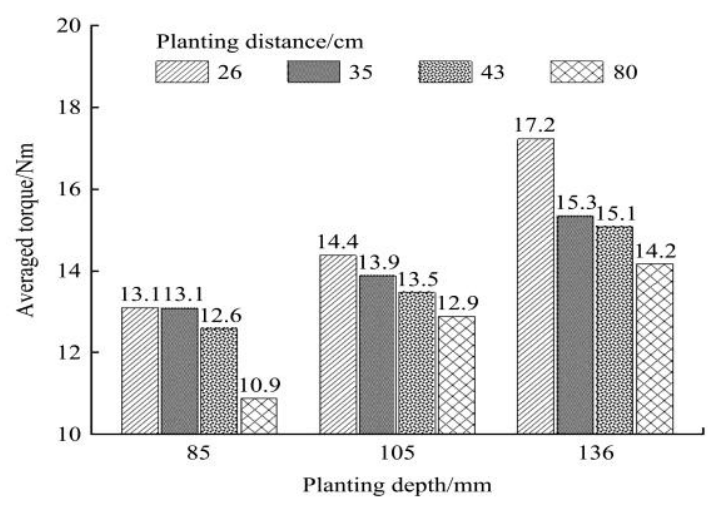

b. Averaged torque

Figure 5 Result of the PTO torque of the transplanter according to the planting distance and depth during planting period 


\subsection{Load spectrum according to the planting conditions}

\subsubsection{Load spectrum according to the planting distance}

Figure 6 showed the load spectrum of the transplanter PTO when the transplanter conducted field operations at planting distances of $26 \mathrm{~cm}, 35 \mathrm{~cm}, 43 \mathrm{~cm}$, and $80 \mathrm{~cm}$ under the three planting depth conditions. The load spectra were constructed by considering the entire life of the transplanter, and the numbers of cycles were within the range of $10^{6}$ to $10^{9}$. In general, the torque ratio increased when the planting distance decreased. The range of the maximum torque ratio of the PTO at a planting distance of $26 \mathrm{~cm}, 35 \mathrm{~cm}, 43 \mathrm{~cm}$, and $80 \mathrm{~cm}$ under the three planting depth conditions was $180 \%-280 \%, 170 \%-280 \%, 160 \%-260 \%$, and $180 \%-200 \%$, respectively. The greatest torque ratio was found at a planting distance of $26 \mathrm{~cm}$. The torque ratios for all planting distances of $26 \mathrm{~cm}, 35 \mathrm{~cm}, 43 \mathrm{~cm}$, and $80 \mathrm{~cm}$ were similar within a high cycle region of $10^{8}$ to $10^{9}$. The torque ratio increased when the planting depth increased in the low cycle region under less than $10^{8}$ cycles at all planting distances except $80 \mathrm{~cm}$. At a planting distance of $80 \mathrm{~cm}$, the torque ratios for planting depths of $105 \mathrm{~mm}$ and $136 \mathrm{~mm}$ were slightly different in the cycles from $10^{7}$ to $10^{8}$. Relatively low PTO loads can occur similarly regardless of the planting depth. When the planting distance decreases, the torque ratio of the transplanter PTO shaft tends to increase.

\subsubsection{Load spectrum according to the planting depth}

Figure 7 showed the load spectrum of the transplanter PTO when the transplanter conducted field operations at planting depths of $85 \mathrm{~mm}, 105 \mathrm{~mm}$, and $136 \mathrm{~mm}$ under the four planting distances. The ranges of the maximum torque ratio of the PTO at planting depths of $85 \mathrm{~mm}, 105 \mathrm{~mm}$, and $136 \mathrm{~mm}$ under the four planting distances were 160\%-200\%, 170\%-220\%, and 200\%-280\%, respectively. The greatest torque ratio was found at a planting depth of $136 \mathrm{~mm}$. The torque ratios at planting depths of $85 \mathrm{~mm}$, $105 \mathrm{~mm}$, and $136 \mathrm{~mm}$ under the four planting distances were similar in a high cycle region of $10^{8}$ to $10^{9}$. However, the torque ratio in the low cycle region under $10^{8}$ increased when the planting depth increased. The higher the planting depth that was applied,
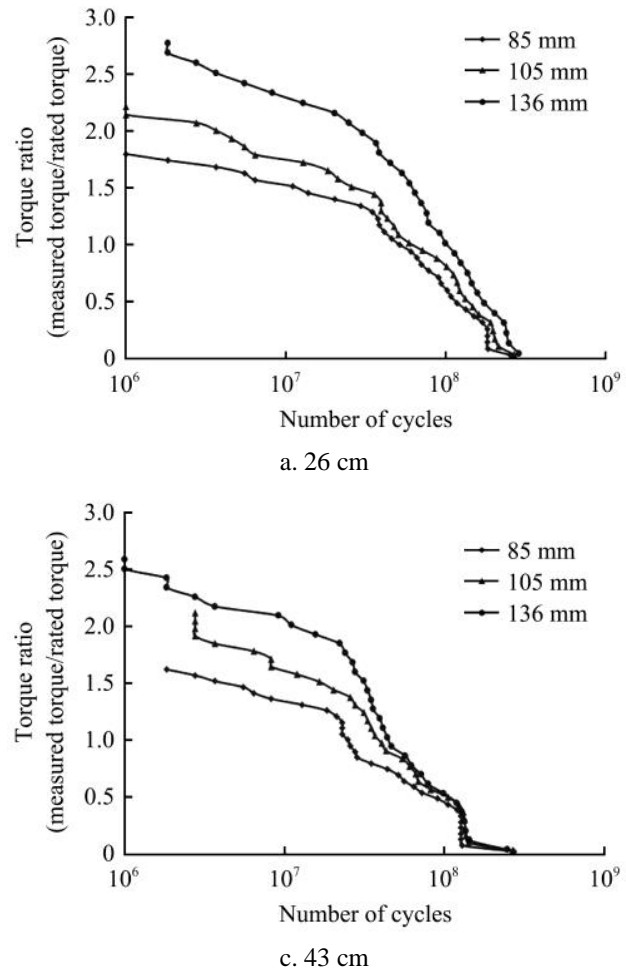

the higher the load on the PTO.

\subsection{Simulation of PTO gear safety factor according to the planting conditions}

The safety factor of the PTO gear was simulated by using the load spectrum analyzed according to the planting conditions. The safety factor of the PTO driving and driven gears were simulated as shown in Figures 8 and 9. The safety factor of the PTO driving gear increased when the planting distance increased at all planting depths. The bending safety factor and contact safety factor of the PTO driving gear at planting depths of $85 \mathrm{~mm}, 105 \mathrm{~mm}$, and $136 \mathrm{~mm}$ increased $123 \%$ and $113 \%, 121 \%$ and $111 \%$, and $133 \%$ and $119 \%$, respectively, when the planting distance was increased from 26 to $80 \mathrm{~cm}$. The bending safety factor has a greater effect on the PTO driving gear than the contact safety factor. The lowest bending safety factor and contact safety factor of the PTO driving gear were 1.66 and 1.00, respectively, at a planting distance of $26 \mathrm{~cm}$ and a planting depth of $136 \mathrm{~mm}$. The results of the safety factor simulation of the PTO driven gear were similar to those for the PTO driving gear. The bending safety factor and contact safety factor of the PTO driven gear at planting depths of $85 \mathrm{~mm}, 105 \mathrm{~mm}$, and $136 \mathrm{~mm}$ increased $123 \%$ and 113\%, 122\% and $111 \%$, and $134 \%$ and $119 \%$, respectively, when the planting distance was increased from 26 to $80 \mathrm{~cm}$. The lowest bending safety factor and contact safety factor of the PTO driven gear were 1.91 and 1.00, respectively, at a planting distance of $26 \mathrm{~cm}$ and a planting depth of $136 \mathrm{~mm}$. In general, farmers use a short planting distance of $26 \mathrm{~cm}$ to transplant many seedlings on the same size of arable land, and use a deep planting depth of $136 \mathrm{~mm}$ so that the seedlings are well transplanted into the ground. The contact safety factor of the driving gear and the driven gear is 1 at a planting distance of $26 \mathrm{~cm}$ and a planting depth of $136 \mathrm{~mm}$. This represents a dangerous condition for the PTO gear and can cause breakage of PTO gear if the farmer performs the transplanting under more severe conditions. Therefore, farmers need to select the appropriate planting conditions when considering the transplanter PTO load.
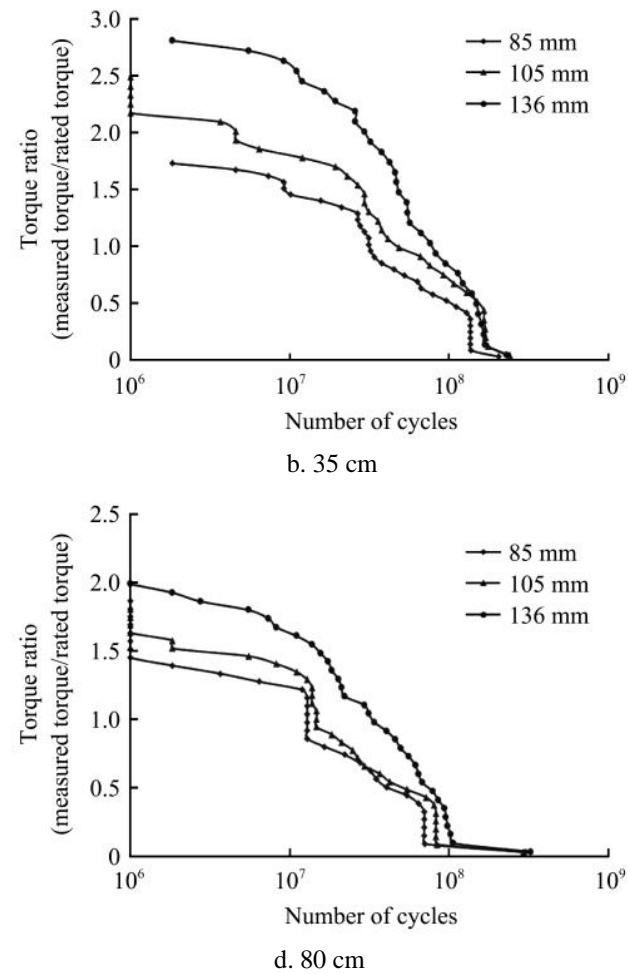

Figure 6 Load spectrum of the PTO according to planting depth at each planting distance 


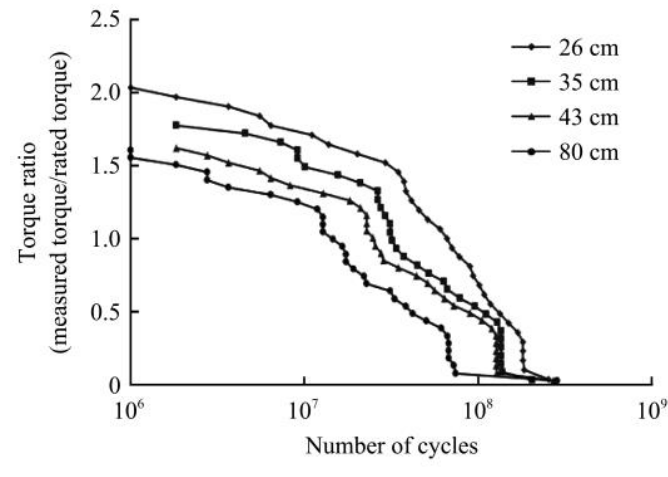

a. $85 \mathrm{~mm}$

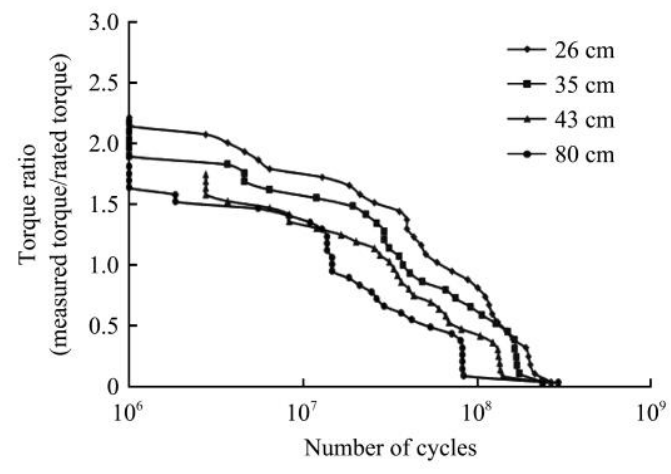

b. $105 \mathrm{~mm}$

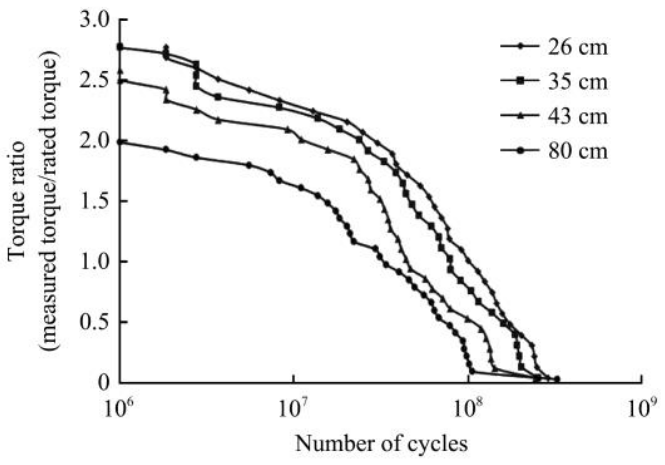

c. $136 \mathrm{~mm}$

Figure 7 Load spectrum of the PTO according to planting distance at each planting depth

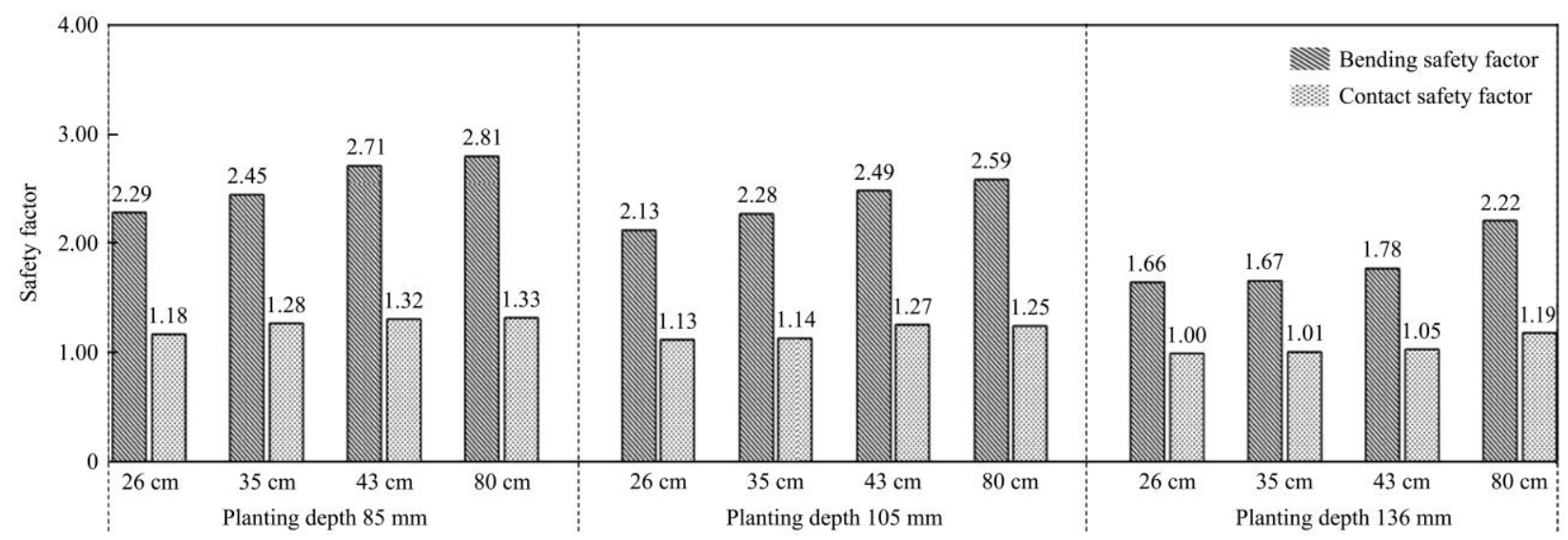

Figure 8 Results of safety factor analysis for the PTO driving gear according to the planting conditions

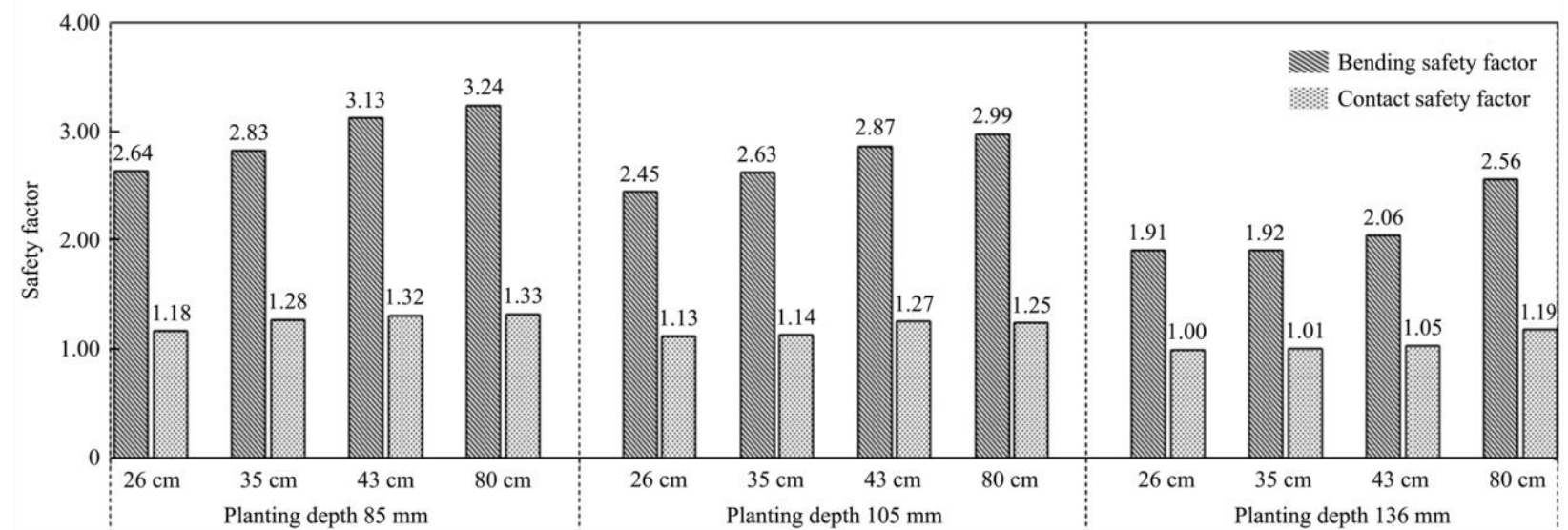

Figure 9 Results of safety factor analysis for the PTO driven gear according to the planting conditions

\section{Conclusions}

This study was conducted to analyze the effects of the planting distance and depth on the PTO load spectrum for the optimal design of a small riding-type transplanter. First, field experiments were conducted at four planting distances $(26 \mathrm{~cm}, 35 \mathrm{~cm}, 43 \mathrm{~cm}$, and $80 \mathrm{~cm})$ and three planting depths $(85 \mathrm{~mm}, 105 \mathrm{~mm}$, and $136 \mathrm{~mm}$ ) in a field with similar soil conditions. Second, the PTO 
load measurement system was developed using a torque sensor, a data acquisition system, and an inverter. Third, load data were analyzed using the rain-flow counting and SWT methods. Fourth, the torque ratio increased when the planting depth increased, and the planting distance decreased in the low cycle region under $10^{8}$ cycles. Finally, the safety factor of the PTO driving and driven gears increased as the planting distance increased at all planting depths. When the planting depth decreased at the same planting distance, the safety factor of the PTO gears increased. Because a transplanter is an agricultural machine used to transplant seedlings into the soil using hoppers that required PTO power, the PTO load of the transplanter may vary depending on the soil conditions. In addition, because the power transmission system and engine power vary depending on the transplanter model, the PTO load differs based on the transplanter model. The results presented in this study appeared to depend on the transplanter model and the soil conditions used in this study, and the results can differ when different transplanter models are used or when the same transplanter model is applied under different soil conditions. However, the process for achieving the optimal design of the transplanter PTO based on the actual field operation load proposed in this study can be applied to other soil and transplanter models. When designing a transplanter PTO, the designer must consider the PTO load according to the planting depth and planting distance, and the operator should be aware that the service life of the transplanter may vary depending on the planting conditions. The results of this study will provide useful information for an optimal design of a transplanter PTO considering the field load data according to the planting distance and depth.

\section{Acknowledgments}

This work was supported by the Industrial Strategic Technology Development Program (10062546, Construction database of work load and development of simulation model for tractor powertrain) funded by the Ministry of Trade, Industry \& Energy (MI, Korea).

\section{[References]}

[1] Park S H, Kim Y J, Choi D K, Kim C K, Kwak T Y, Cho S C. Development of walking type Chinese cabbage Transplanter. Journal of Biosystems Engineering, 2005; 30(2): 81-88.

[2] Lim J H, Park S Y, Chae W B, Kim S K, Choi S K, Yang E Y, et al. Seedling conditions for kimchi cabbage, head lettuce, cabbage and broccoli for a riding-type transplanter. Journal of Biosystems Engineering, 2017; 42(2): 104-111

[3] Gen Consulting Company. Global Rice Transplanter Market Outlook 2017-2022. Radiant Insights, Inc. 2018. https://www.radiantinsights. com/research/global-rice-transplanter-market-outlook-2017-2022. Accessed on [2018-04-02].

[4] Kim W S, Chung S O, Choi C H, Cho J S, Choi D S, Kim Y S, et al. Analysis of the PTO torque of a transplanter by planting condition. Journal of Biosystems Engineering, 2016; 41(4): 313-318.

[5] Lim S J, Kwon H J, Kang Y S, Lee P U, Kim T J, Kim Y J, et al. Power analysis of a 3-kW Class Motor-Driven Multipurpose Walking-Type Transplanter. Journal of Biosystems Engineering, 2019; 1(2): 135-145.

[6] Gaikwad P B, Shahare P U, Pathak S V, Aware V V. Development and performance evaluation of four row self-propelled paddy transplanter. International Journal of Agricultural Engineering, 2015; 8(1): 9-14.
[7] Kim W S, Kim Y S, Kim Y J, Choi C H, Inoue E, Okayasu T. Analysis of the load of a transplanter PTO shaft based on the planting distance. J. Fac. Agr., Kyushu Univ, 2018; 63(1): 97-102.

[8] Kim W S, Kim Y J, Park S U, Hong S J, Kim Y S. Evaluation of PTO severeness for $78 \mathrm{~kW}$-class tractor according to disk plow tillage and rotary tillage. J. Drive Control, 2019; 16(4): 23-31.

[9] Hong S J, Park S J, Kim W S, Kim Y J, Park S U. Analysis of the axle load of an agricultural tractor during plow tillage and harrowing. Korean Journal of Agricultural Science, 2016; 43(4): 665-669.

[10] Kim T J, Kim W S, Kim Y S, Chung S O, Park S U, Hong S J, et al Strength analysis of mechanical transmission using equivalent torque of plow tillage of an $82 \mathrm{~kW}$-class tractor. Korean Journal of Agricultural Science, 2019; 46(4): 723-735.

[11] Kim W S, Kim Y S, Kim T J, Park S U, Choi Y, Choi I S, et al. Analysis of power requirement of $78 \mathrm{~kW}$ class agricultural tractor according to the major field operation. Trans. Korean Soc. Mech. Eng. A, 2019; 43(12): 911-922.

[12] Kim D C, Ryu I H, Kim K U. Analysis of tractor transmission and driving axle loads. Transactions of the ASAE, 2001; 44(4): 751-757.

[13] Jang J H, Chung S O, Choi C H, Park Y J, Chun W K, Kim S I, et al Effects of PTO gear face width on safety factors. Korean Journal of Agricultural Science, 2016; 43(4): 650-655.

[14] Lee D H, Kim Y J, Chung S O, Choi C H, Lee K H, Shin B S. Analysis of the PTO load of a $75 \mathrm{~kW}$ agricultural tractor during rotary tillage and baler operation in Korean upland fields. Journal of Terramechanics, 2015; 60: 75-83.

[15] Kim D H, Kim D C, Kim S H, Shin B S. Development of stem-cutting transplanter for short-term rotation coppice. Journal of Biosystems Engineering, 2010; 35(1): 37-45.

[16] Min Y B, Moon S D. Automatic feeding and transplanting mechanism for plug seedling transplanter. Journal of Biosystems Engineering, 1998; 23(3): 259-270.

[17] Park S H, Cho S C, Kim J Y, Choi D K, Kim C K, Kwak T Y. Development of rotary type transplanting device for vegetable transplanter. Journal of Biosystems Engineering, 2005; 30(3): 135-140.

[18] Siddique A A, Kim W S, Baek S Y, Kim Y S, Choi C H, Kim Y J, et al Determination of PID coefficients for the ascending and descending system using proportional valve of a rice transplanter. Journal of Biosystems Engineering, 2018; 43(4): 331-341.

[19] Kim Y S, Kim T J, Kim Y J, Lee S D, Park S U, Kim W S. Development of a real-time tillage depth measurement system for agricultural tractors: application to the effect analysis of tillage depth on draft force during plow tillage. Sensors, 2020; 20(3): 912.

[20] Lee D H, Kim Y J, Choi C H, Chung S O, Nam Y S, So J H. Evaluation of operator visibility in three different cabins type Far-East combine harvesters. Int J Agric \& Biol Eng, 2016; 9(4): 33-44.

[21] Kim Y S, Lee P U, Kim W S, Kwon O W, Kim C W, Lee K H, et al. Strength analysis of a PTO (power take-off) gear-train of a multi-purpose cultivator during a rotary ditching operation. Energies, 2019; 12(1100): $1-14$.

[22] Hong N. A modified Rainflow counting method. Int. J. Fatigue, 1991; 13(6): 465-469.

[23] Glinka G, Kam J C P. Rainflow counting algorithm for very long stress histories. International Journal of Fatigue, 1987; 9(4): 223-228.

[24] Lee J S, Yu H Y, Lee G T, Kim D C. Analysis of load spectrum of 70 $\mathrm{kW}$-class tractor for plowing operation. Journal of Agriculture \& Life Science, 2014; 45(1): 18-22.

[25] Kim Y J, Chung S O, Choi C H. Effects of gear selection of an agricultural tractor on transmission and PTO load during rotary tillage. Soil \& Tillage Research, 2013; 134: 90-96.

[26] Lee P U. Analysis of work load and fatigue life of PTO gears for multi-purpose cultivator. MS Thesis. Daejeon: Chungnam National University, 2017, 8. 53p.

[27] Lee P U, Chung S O, Choi C H, Joo J H, Rhee J Y, Choi Y S, et al. Load capacity simulation of an agricultural gear reducer by surface heat treatment. Korean Journal of Agricultural Science, 2016; 43(4): 656-664. 